\title{
A Study to Assess the Effectiveness of Structured Teaching Program regarding Knowledge on Non- Communicable Diseases among Class IV Workers
}

\author{
Prasanna Deshpande ${ }^{1}$ Tukaram B. Zagade ${ }^{2}$ \\ ${ }^{1}$ Principal, KLES Institute of Nursing Sciences, Ankola UK
}

${ }^{2}$ Professor, Department of Medical-Surgical Nursing Krishna Institute of Nursing Sciences Krishna Institute of Medical Sciences Deemed University, Karad Maharastra-415539

\begin{abstract}
Non communicable disease is the killer disease"Non communicable disease is a medical condition or disease that can defined as non infectious and non transmissible among people. The purpose of this study was to assess the effectiveness of planned teaching programme on knowledge regarding knowledge on non communicable diseases among class IV workers of KLE Institute, Ankola. Problem Statement: "A study to assess the effectiveness of structured teaching program regarding knowledge on non communicable diseases among class IV workers of KLE Institute, Ankola.” Objectives: To assess the level of knowledge regarding non communicable diseases among class IV workers KLE'S Institute Ankola. To associate pre test level of knowledge regarding non communicable diseases among class IV workers with demographic variable in KLE'S Institute Ankola. To assess the effectiveness of structured teaching programme regarding knowledge on non communicable diseases among class IV workers. To associate the post test level of knowledge of class IV workers regarding non-communicable diseases with demographic variable in KLE'S Institute Ankola. Research Methodology: Research approach : An evaluative approach, Research design : One group pre test, post test design, Research setting : K.L.E' Institute, Ankola, Population : Class IV workers of KLE'S Institute, Ankola, Sample size : 30 workers, Sampling technique : Purposive sampling technique, Tool : Structured questionnaire. Result: The paired 't' test established at 0.05 level of significance revealed that mean post test knowledge score of the sample is significantly higher than their mean pre-test knowledge score which signifies that calculated value is greater than the table value. Conclusion: The overall findings of the study revealed that there was a significant increase in knowledge level of class IV workers after administration of structured teaching regarding NCDs. The knowledge regarding $\mathrm{NCDs}$, introduction, types, cause, investigation, treatment and prevention regarding NCDs which rose after the structured teaching.
\end{abstract}

Keywords: Effectiveness, Structured teaching program, Knowledge, Non-communicable diseases, Class IV workers

\section{Introduction}

"Non communicable disease is the killer disease "Non communicable disease is a medical condition or disease that can defined as non infectious and non transmissible among people.

Non communicable disease can refers to chronic diseases which last for long period of time and prognoses slowly sometimes, incidence result in rapid deaths such as seen in certain type of disease such as auto immune disease, heart disease, stroke, most cancers, diabetes, chronic kidney disease, Alzheimer's disease and many more. Which sometime (incorrectly) referred to synonymous with chronic diseases NCD are distingushional, because their noninfectious causes. Not necessary by their duration, such as HIV/AIDs, are caused by transmissible infection. Chronic disease needs chronic care management. As do all disease that are slow to develop and of long duration.

The world health organization (WHO) reports NCDs to be by further leading cause of death in the world, representing over $60 \%$ of old deaths, out of the 36 million people. Who died from NCDs in 2005 half where under age 70 and half were women of the 57 million global deaths in 2008, 36 million were such incidence .Then is approximately $63 \%$ of total death worldwide risk factors such aspersons background, life style and environment are known to increases the likely hood of certain NCDs. Every yearly at least 5 million people die because of tobacco use. About 2.8 million die from overweight high cholesterol accounts for roughly 2.6 million die because of high blood pressure.

\section{Need for Study}

This is an innovative distance learning that allows you to combine work with gaining a qualification relevant to a pressing global issue.

Cardiovascular diseases, diabetes and cancer collectively known as non-communicable diseases .NCDS known as non communicable diseases. There are on the increase globally. There are no longer diseases of the affluent $80 \%$ of NCD death now occur in low and middle income countries.

These conditions are largely preventable unhealthy diets; physical inactivity and alcohol conception are all contributing factors. As globalization continues to change people's life style, the prevention and management of NCD is arguably the greatest global health challenge of $21^{\text {st }}$ century.

In September 2011 the1st ever United Nations summit on NCD was held, putting the issue on the political agenda and calling for stronger international collaboration to tackle this epidemic. 


\section{International Journal of Science and Research (IJSR) \\ ISSN (Online): 2319-7064}

Index Copernicus Value (2013): 6.14 | Impact Factor (2015): 6.391

Some times NCDs results in rapid such as seen in certain types of diseases such as autoimmune diseases, heart diseases, stroke, most cancers, asthma, diabetes, cataracts and many more while sometimes(incorrectly) referred to as synonymous with chronic diseases.

NCDs are distinguished only by their non-infectious cause, not necessarily by their duration.

Some chronic diseases of long duration, such some chronic diseases of long duration such as HIV/AIDs are caused by transmittable infection chronic diseases require chronic care management as do all diseases that are slow to develop and of long duration.

Thus, should policy makers and communities mobilize and make prevention and targeted treatment of such disease a priority. Sustainable measures can be implemented to stagnate (and eventually even reverse) this emerging global health threat. Potential measures currently being discussed by the (WHO) - food and agriculture organization includes reducing the levels of salt in foods, limiting inappropriate marketing for unhealthy foods and non-alcoholic beverages to children, imposing controls on harmful alcohol use, raising taxes on tobacco, and curbing legislation to curve smoking in public places.

\section{Review of Literature}

Review of related literature is a systematic identification, location, scrutiny and summary of written materials that contain information on research problems. Review of literature is a key step in research refers to an extensive, exhaustive and systematic examination of publications relevant to research project. It is an essential part of every research, which helps to support the hypothesis under the study and critically analyze the structure and content of the research project.

The review of literature is a broad, comprehensive, in depth, systematic and critical review of scholarly, publications, unpublished scholarly print materials, also visual materials and personal communications. Reviewing and evaluating the literature is central to the research process. Review of literature is a key step in research process. It is an extensive, exhaustive and systematic examination of earlier or contemporary publication relevant to research. It is essential for the research study and the researcher to analyze the existing knowledge before going into a new area of study. This will help make a stepping stone in the progress of study.

A pilot study was conducted to examine the reach, implementation, and efficacy of a 6 month life style program implemented in primary care by nurse practitioners for adults at risk of type 2 diabetes in rural area Shimoga. Program reached a diverse, obese, and moderately low income sample. The nursing practitioners were able to successfully implement the protocols. The average length of the program was 9.3 months. Attendance was high (98\%) and attrition was low (12\%). The nursing practitioners were able to adopt the educational, behavioral, and psychosocial strategies of the intervention easily. Motivational interviewing was more difficult for nursing practitioners.

Twenty-five percent of lifestyle participants met treatment goals of $5 \%$ weight loss compared with $11 \%$ of standard care participants. With the increasing prevalence of obesity and T2D risk, many adults would benefit from a preventive intervention.

Literature related to engagement of adolescents in a health communication program to prevent non communicable diseases multiplicadoresjovenes, Lima Peru 2011.

In Lima, Peru's capital, the proportion of adolescents aged 15 to 19 is $9.3 \%$ of the city's population and school emollient rates are high. The prevalence of excess weight in Peruvian adolescence is $14.2 \%$ and prevalence has not declined in recent areas. (Several risk factors of NCDs including obesity are associated with behavior established in infancy that persists throughout adolescence and adulthood.) The multiplicadoresjovenes (young multiplier) project was conducted among adolescents agent 15 to 17 from 9 public secondary schools in peri-urban areas of Lima Peru. The project provided basic communication tools and knowledge and NCD prevention and public health research to adolescents during 16 weekly participatory sessions to enable them to design and disseminate healthful lifestyle to their school peers. 30 of 45 participants finished the program. Seven communication campaigns were designed and implemented in schools reaching 1,200 students. The participants gained motivation, increased knowledge and developed communication skills that were combined to implement healthful lifestyle promotion campaign.

\section{Research Methodology}

Research methodology is a way to solve the research problems systematically. It involves a procedure in which the researchers start from initial identification of the problem to its final conclusion.

\section{Research Approach}

Research approach indicates that basic procedure for conducting the study in view of nature of the problem. The appropriate choice of research approach depends on the purpose of the study.

'Approach to research is an umbrella which covers the basic procedure for conducting research

An evaluative approach was felt to be appropriative for the study undertaking, since it was aimed at evaluate the knowledge regarding NCDs among class IV workers of KLES institute, Ankola.

\section{Research Design}

The research design is the plan, structure and question strategy of investigators answering the research questions in the overall plan on blue print in which researchers select to carry out their study.

In this study, one group pre-test post test design was used to evaluate the knowledge of class IV workers on non communicable disease.

\section{Research Setting}

\section{Volume 5 Issue 6, June 2016} www.ijsr.net 


\section{International Journal of Science and Research (IJSR) \\ ISSN (Online): 2319-7064}

Index Copernicus Value (2013): 6.14 | Impact Factor (2015): 6.391

Setting is depending upon the study topic and researcher choice, for the present study KLE'S Institute, Ankola is selected as research setting to conduct the present study.

The setting was selected on the basis of:

Availability of samples.

Feasibility of conducting the study.

\section{Variables under Study}

A variable is characteristic of attribute of an events or phenomenon to be observed which can be measured. Research variables are concepts atvarious level of abstraction that are measured,manipulated or controlled in a study.

\section{Population}

A population is a group, in which a research study is conducted, having at least one characteristic common. The nature of the population being studied needs to be specified in problem statement. Population is an aggregate an elements showing some common set of criteria. In this study population were class IV workers of KLEs Institute, Ankola.

\section{Samples}

A sample is a sub set of population which selected to participate in particular study. In this study samples were 30 class IV workers of KLEs Institute Ankola.

\section{Sampling}

Sampling is a process of selecting a group of people, event or portion of population to represent the population. In this study sampling method used was purposive sampling which was a type of non purposive sampling.

\section{Purposive sampling}

This indicates selection of design by choice not by chance. In purposive sampling the sample is chosen which is thought to be typical of the universe with regard to the characteristic and investigation.

It is selected for the study the researcher of the convenience. The class IV workers KLE'S Institute Ankola, were selected to fulfill the sampling criteria and conduct to study.

\section{Sample size}

30 class IV workers of KLEs Institute Ankola who fulfill the inclusion criteria of study.

\section{Inclusion criteria}

The criteria that specify the population characteristic are the inclusion criteria of the study include:-

Class IV workers who were present during the period of data collection.

Class IV workers who were willing to participate in the study.

Class IV workers who know to read and write Kannada.

\section{Exclusion Criteria}

A population define in terms of characteristics that it must not posses. The exclusion criteria of this study includes:-

Class IV workers who were not willing to participate in the study.

Class IV workers were not available during data collection.

\section{Demographic Variable}

Independent Variable:-Baseline knowledge of class IV workers regarding Non- communicable diseases.

\section{Analysis and Interpretation}

This chapter deals with statistical analysis. It is a process of analyzing and synthesizing the data such a way that research question will be answered; also it is a method rendering quantitative information in a meaningful and intelligible manner to enabling the research to organize, interpret and communicate informant meaningfully.

The data collected to assess the knowledge regarding non communicable disease were grouped and analyzed using descriptive and inferential statistics. Tables and figures used to explain the results.

In this study, analysis and interpretation of the data were based on the data collected through structured questionnaire from 30 samples of KLE's Institute, Ankola.

\section{Problem Statement}

A study to assess the effectiveness of structured teaching programme on knowledge regarding non communication disease among class IV workers of KLE's Institute, Ankola.

\section{Objectives of the Study}

- To assess the knowledge regarding non communicable disease among selected class IV workers.

- To prepare and administer the structured teaching on non communicable disease.

- To evaluate the effectiveness of structured teaching on non communicable disease.

- To associate the post test level of knowledge of class IV workers regarding non-communicable diseases with demographic variable in KLE'S Institute Ankola.

\section{Hypothesis}

H1:- There will be significant statistical association between pre-test knowledge scores on non-communicable among class IV workers with selected demographic variable of selected class IV workers of KLE's Institute, Ankola at 0.05 level of significance.

$\mathrm{H} 2$ :-There will be significant gain in knowledge on NCDs among selected class IV workers working in KLEs institute, Ankola through Structured teaching program

\section{Presentation Of Data}

The data was entered into a master sheet for tabulation and statistical processing. The analysis of data was organized and presented under the following headings.

Section A: Distribution of samples demographic characteristics according to baseline data.

Section B: Analysis and interpretation of findings related to knowledge of class IV workers of KLE's Institute, Ankola.

Section A: Findings Related to Socio-Demographic
Variables of Class IV Workers
Table 1
\begin{tabular}{|c|c|c|c|}
\hline Sl. & Base line data & Frequency & $\begin{array}{c}\text { Percentage } \\
(\%)\end{array}$ \\
\hline
\end{tabular}

Volume 5 Issue 6, June 2016 www.ijsr.net 
International Journal of Science and Research (IJSR)

ISSN (Online): 2319-7064

Index Copernicus Value (2013): 6.14 | Impact Factor (2015): 6.391

\begin{tabular}{|c|c|c|c|}
\hline 1 & $\begin{array}{l}\text { Age in year } \\
20-30 \\
31-40 \\
41-50 \\
\text { Above } 50\end{array}$ & $\begin{array}{l}02 \\
14 \\
12 \\
02\end{array}$ & $\begin{array}{l}6.66 \% \\
46.66 \% \\
40.66 \% \\
6.66 \% \\
\end{array}$ \\
\hline 2 & $\begin{array}{l}\text { Gender } \\
\text { Male } \\
\text { Female }\end{array}$ & $\begin{array}{l}18 \\
12\end{array}$ & $\begin{array}{l}60 \% \\
40 \%\end{array}$ \\
\hline 3 & $\begin{array}{l}\text { Religion } \\
\text { Hindu } \\
\text { Muslim } \\
\text { Christian } \\
\text { If any other }\end{array}$ & $\begin{array}{l}30 \\
00 \\
00 \\
00\end{array}$ & $\begin{array}{l}100 \% \\
00 \\
00 \\
00\end{array}$ \\
\hline 4 & $\begin{array}{l}\text { Marital status } \\
\text { Single } \\
\text { Married } \\
\text { Divorced } \\
\text { Widow }\end{array}$ & $\begin{array}{l}05 \\
20 \\
00 \\
05\end{array}$ & $\begin{array}{l}16.66 \% \\
66.66 \% \\
00 \\
16.66 \%\end{array}$ \\
\hline 5 & $\begin{array}{l}\text { Family income per year } \\
\text { Less than } 10,000 \\
10,000-20,000 \\
200^{\prime} 000-50,000\end{array}$ & $\begin{array}{l}00 \\
23 \\
07\end{array}$ & $\begin{array}{l}00 \\
76.66 \% \\
23.33 \% \\
\end{array}$ \\
\hline 6 & $\begin{array}{l}\text { Any previous knowledge } \\
\text { about non communicable } \\
\text { diseases } \\
\text { Yes } \\
\text { No }\end{array}$ & $\begin{array}{l}16 \\
14\end{array}$ & $\begin{array}{l}53.33 \% \\
46.66 \%\end{array}$ \\
\hline 7 & $\begin{array}{l}\text { If yes from mass media } \\
\text { information is gained } \\
\text { Television } \\
\text { News paper } \\
\text { Magazine } \\
\text { Internet } \\
\text { Family or friends } \\
\text { Doctor or health } \\
\text { professional } \\
\text { If any other }\end{array}$ & $\begin{array}{l}06 \\
03 \\
00 \\
01 \\
00 \\
05 \\
01\end{array}$ & $\begin{array}{l}20 \% \\
10 \% \\
00 \\
3.33 \% \\
00 \\
16.66 \% \\
3.33 \%\end{array}$ \\
\hline 8 & $\begin{array}{l}\text { Have you come across } \\
\text { any non communicable } \\
\text { disease } \\
\text { Yes } \\
\text { No }\end{array}$ & $\begin{array}{l}03 \\
27\end{array}$ & $\begin{array}{l}10 \% \\
90 \%\end{array}$ \\
\hline
\end{tabular}

Majority of class IV workers has not come across any non communicable disease $17(6.66 \%)$ and has come across 03 $(10 \%)$.

Section B: Analysis and interpretation of the finding related to knowledge of class IV workers regarding non communicable diseases.

Table 2: Distribution of mean, median, mode and standard deviation of pre-test knowledge score on non communicable

\begin{tabular}{|l|l|l|l|l|}
\multicolumn{5}{c|}{ diseases, N=30 } \\
\hline Sl. No & Mean & Median & Mode & Standard deviation \\
\hline 1 & 12.3667 & 12.5 & 2.1 & 4.1976 \\
\hline
\end{tabular}

Table- 2 represents the distribution of pre- test knowledge score. The knowledge was distributed with a mean 12.36 , median 12.5, mode 2.1 and standard deviation 4.19

Table 3: Distribution of mean, median, mode and standard deviation of post-test knowledge score on non communicable diseases, $\mathrm{N}=30$

\begin{tabular}{|c|c|c|c|c|}
\hline Sl. No & Mean & Median & Mode & Standard deviation \\
\hline 1 & 22.9 & 23.9 & 28 & 7.45 \\
\hline
\end{tabular}

Table-3 represents the distribution of post- test knowledge score. The knowledge was distributed with a mean 22.9, median 23.9, mode 28 and standard deviation 7.45 .

The data presented in the table 1 indicated

Majority of class IV workers 14(46.66\%) belonged to age group of 30-40years and minimum number of class IV workers $02(6.66 \%)$ were $20-30$ and above 50years.

Class IV workers were male $18(60.66 \%)$ and female $12(40.00 \%)$

All of the class IV workers were Hindu 30 (100\%).

The marital status of class IV workers were single 05 (16.66\%), married $20(66.66 \%)$, widow 05 (16.66\%) and no divorced.

Majority of the class VI workers had the family income of $10,000-20,000$ per year $23(76.66 \%)$, had family income of $25,000-50,00007(23.33 \%)$.

Majority does not have the previous knowledge of NCDs $17(56.66 \%)$ and have previous knowledge of NCDs is $13(43.33 \%)$.

Some of the class IV workers had the knowledge through television $6(20 \%)$, through news papers 03(10\%) through internet $1(3.33 \%)$, through doctors or health professional $5(16.66 \%)$ and other source $1(3.33 \%)$. 


\section{International Journal of Science and Research (IJSR) \\ ISSN (Online): 2319-7064}

Index Copernicus Value (2013): 6.14 | Impact Factor (2015): 6.391

Table 4: Frequency and percentage distribution of pre-test knowledge score of sampling regarding NCDs, $\mathrm{N}=30$

\begin{tabular}{|c|c|c|c|c|}
\hline Sl. No & $\begin{array}{c}\text { Level of } \\
\text { knowledge }\end{array}$ & Score range & Frequency & Percentage \\
\hline 1 & Poor & $1-9$ & 08 & $26.66 \%$ \\
\hline 2 & Average & $10-18$ & 20 & $66.66 \%$ \\
\hline 3 & Good & $19-30$ & 02 & $06.66 \%$ \\
\hline
\end{tabular}

Table -4 reveal that all sample $6.66 \%$ (02) had good knowledge score, $66.66 \%$ (20) had average knowledge and $26.6 \%$ (08) had poor knowledge.

Table 5: Frequency and percentage distribution of post-test knowledge score of sampling regarding NCDs, $\mathrm{N}=30$

\begin{tabular}{|c|c|c|c|c|}
\hline S1. No & $\begin{array}{c}\text { Level of } \\
\text { knowledge }\end{array}$ & Score range & Frequency & Percentage \\
\hline 1 & Poor & $1-20$ & 06 & $20 \%$ \\
\hline 2 & Average & $21-24$ & 14 & $46.66 \%$ \\
\hline 3 & Good & $25-30$ & 10 & $33.33 \%$ \\
\hline
\end{tabular}

Table 5 reveals that samples $33.33 \%$ (10) had good knowledge, $46.66 \%$ (14) had average knowledge and $20 \%$ (06) had poor knowledge.

Frequency and percentage distribution showing the difference between pre-test and post-test knowledge score of samples regarding NCDs

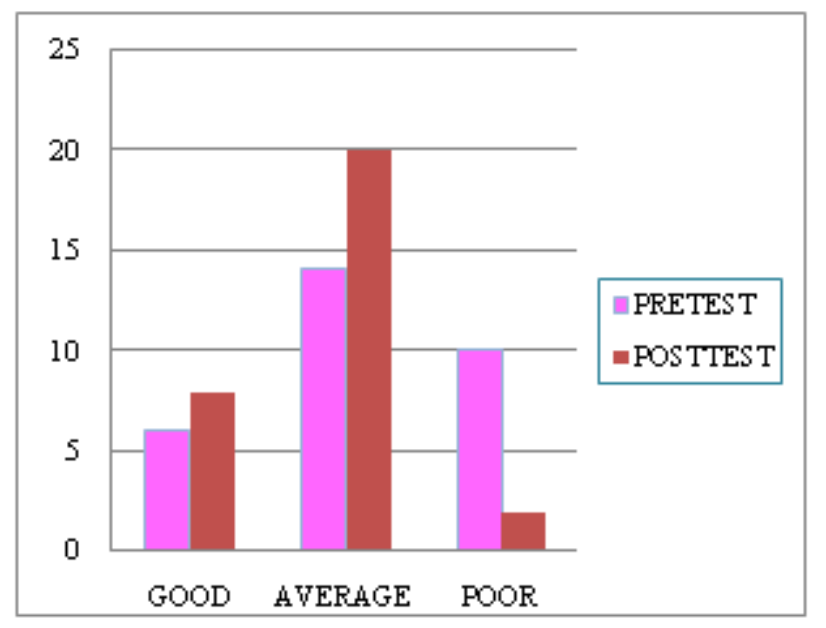

Section C: Association between pre-test knowledge scores on non communicable diseases and selected demographic variables

\begin{tabular}{|c|c|c|c|c|c|}
\hline $\begin{array}{l}\text { Sl. } \\
\text { No. }\end{array}$ & $\begin{array}{c}\text { Demographic } \\
\text { Variables }\end{array}$ & $\begin{array}{c}\text { Chi- } \\
\text { Square } \\
\text { Value }\end{array}$ & df & $\begin{array}{l}\text { Table } \\
\text { Value }\end{array}$ & Significance \\
\hline 1. & Age & 73.02 & 3 & 7.81 & $S$ \\
\hline 2. & Gender & 21.6 & 1 & 3.84 & NS \\
\hline 3. & Religion & 0 & 3 & 7.81 & $\mathrm{~S}$ \\
\hline 4. & Marital status & 45.22 & 3 & 7.81 & NS \\
\hline 5. & Family income Per year & 3.26 & 2 & 5.99 & $\mathrm{~S}$ \\
\hline 6. & Previous Knowledge & 19.28 & 1 & 3.84 & NS \\
\hline 7. & Source of information & 127.17 & 6 & 12.6 & NS \\
\hline 8. & Experienced any NCDs & 24.6 & 1 & 3.84 & $\mathrm{NS}$ \\
\hline
\end{tabular}

H1:- There will be significant association between pre-test knowledge score on NCDs with selected demographic variables of selected class IV workers at 0.05 level of significance.
$\mathrm{H} 2$ :- There will be significant gain in knowledge on NCD among selected class IV workers working in KLE.S institute of health sciences; Ankola through structured teaching programme.

Hence the hypothesis is $\mathrm{H} 1$ which states that there will be statistical significance association between pre-test knowledge scores on NCDs with demographic variables of class IV workers at 0.0 level of significance was accepted.

Section D: Effectiveness of structured teaching program on non communicable diseases by paired ' $t$ ' test:

Table 7: Mean, standard error of deviation, degree of freedom and ' $t$ ' value of post-test and pre-test knowledge scores of samples.

\begin{tabular}{|l|l|l|l|l|l|l|}
\hline Parameters & Mean & $\begin{array}{l}\text { Difference } \\
\text { of Mean }\end{array}$ & SED & 't'cal & $\begin{array}{c}\text { 't' } \\
\text { table }\end{array}$ & $d f$ \\
\hline PRE-TEST & 12.36 & 10.54 & 3.26 & 12.33 & 1.69 & 29 \\
\hline POST-TEST & 22.9 & 10.54 &
\end{tabular}

The data and the table shows that mean post-test knowledge scores of the sample is significantly higher than mean pretest knowledge scores i.e the ' $t$ ' table $(29)=1.69$ and the calculated value ' $\mathrm{t}$ ' $=12.33, \mathrm{p}<0.05$ which shows that calculated value is greater than the table value.

Hence alternative hypothesis [H1] was accepted indicating that there will be significant gain in knowledge on NCDs among selected class IV workers in KLES institute, Ankola through STP.

\section{Discussion}

The present study was conducted to assess the effectiveness of STP on non communicable diseases among class IV workers of KLEs Institute, Ankola. It is pre-experimental in nature the major findings depend on the objectives of the study. The primary purpose of the study was to determine the knowledge of class IV workers regarding NCDs and to prepare and administer the STP teaching program. It also aims to evaluate the effectiveness of STP.

The tool used for the study consist of 2 sections -

SECTION-A: Demographic data

SECTION-B: Structured questionnaire

The major findings of the study are discussed under the following sections.

\section{SECTION - A}

\section{Socio Demographic Data}

Majority of class IV workers $14(46.66 \%)$ belonged to age group of 30-40years and minimum number of class IV workers $02(6.66 \%)$ were $20-30$ and above 50years.

Class IV workers were male $18(60.66 \%)$ and female $12(40.00 \%)$

All of the class IV workers were Hindu 30 (100\%).

The marital status of class IV workers were single 05 (16.66\%), married 20 (66.66\%), widow $05(16.66 \%)$ and no divorced. Majority of the class VI workers had the family 


\section{International Journal of Science and Research (IJSR) \\ ISSN (Online): 2319-7064}

Index Copernicus Value (2013): 6.14 | Impact Factor (2015): 6.391

income of 10,000-20,000 per year $23(76.66 \%)$, had family income of $25,000-50,00007(23.33 \%)$.

Majority does not have the previous knowledge of NCDs $17(56.66 \%)$ and have previous knowledge of NCDs is $13(43.33 \%)$.

Some of the class IV workers had the knowledge through television $6(20 \%)$, through news papers $03(10 \%)$ through internet $1(3.33 \%)$, through doctors or health professional $5(16.66 \%)$ and other source $1(3.33 \%)$.

Majority of class IV workers has not come across any non communicable disease $17(6.66 \%)$ and has come across 03 $(10 \%)$.

\section{SECTION - B}

SECTION 1: Description of pre-test and post- test knowledge scores.

The assessment of pre- test knowledge among class IV workers regarding NCDs revealed that $6.6 \%$ of students had good knowledge, $66.6 \%$ had an average level of knowledge where as remaining $26.6 \%$ has poor knowledge.

The assessment of post- test knowledge among class IV workers regarding NCDs revealed that $33.3 \%$ of students had good knowledge, $43.3 \%$ had an average level of knowledge where as remaining $20 \%$ has poor knowledge.

SECTION 2: Effectiveness of STP on knowledge of class IV workers.

Paired ' $t$ ' test was established at 0.05 level of significance denotes the effectiveness of STP on knowledge of class IV workers regarding NCDs.

The statistical analysis demonstrated that an increase in knowledge level of class IV workers regarding NCDs was significant with ' $t$ ' calculated value of 12.33 which is greater than ' $t$ ' tabulated value 1.699. So the STP was effective in improving the knowledge level among the class IV workers regarding NCDs.

SECTION 3- Association between knowledge and demography scores.

Chi-square established at 0.05 level of significance denotes the association between the knowledge and demographic variables age, gender, religion, marital status, family income, previous knowledge, source of information and any NCDS. However the calculated value for each (73.02), for gender (21.6), for marital status (45.22) and for previous knowledge (19.28), source of information (127.17) and experienced NCDs (24.6) were greater than tabulated value hence there was an association found with this demographic variables. But that of religion (00) and family income per year (3.26) were less than the tabulated values hence there was no significant association found with this demographic variables.

\section{Conclusion}

The present study was undertaken to evaluate the effectiveness of Structured Teaching Programme on knowledge regarding NCDs and to associate it with the selected demographic variables.
The following conclusions were based on the findings. The result was described by using descriptive and inferential statistics.

The study indicates that majority of subjects $46.66 \%$ (14) belonged to age group of 30-40 years. The subjects were male $60.66 \%$ (18) and female $40 \%$ (20). All of the subjects were Hindu $100 \%$ (30). Majority of the subject were married $66.66 \%$ (20). The family income of the majority of the subjects $76.66 \%$ (23) were 10,000-25,000 per year.

Maximum workers $56.66 \%$ have previous knowledge about NCDs. The source of information of maximum workers was $20 \%$ (6) were through television and others.

The paired ' $t$ ' test established at 0.05 level of significance revealed that mean posttest knowledge of the sample is significantly higher than their mean pretest knowledge which shows that calculated value is greater than the table value. Hence null hypothesis $\left(\mathrm{H}_{\mathrm{o}}\right)$ was rejected and research hypothesis was accepted indicating that there was significant gain in knowledge on NCDs through Structured teaching programme.

The chi-square established at 0.05 level of significance denotes the association between the knowledge and demographic variables like age, gender, marital status, previous knowledge, source of information and experienced NCDs were more than the tabulated value hence an association was found among demographic variables, but that of religion and family income per year was less than the tabulated value hence no association was found.

\section{Summary}

This chapter deals with summary of the study and its major findings. As well as some of the recommendations that can be taken up for further studies in the same field.

\section{Statement of the Problem}

"A study to assess the effectiveness of structured teaching program regarding knowledge on non communicable diseases among class IV workers of KLE Institute, Ankola."

\section{Objectives of the Study}

1) To assess the level of knowledge regarding non communicable diseases among class IV workers KLE'S Institute Ankola.

2) To associate pre test level of knowledge regarding non communicable diseases among class IV workers with demographic variable in KLE'S Institute Ankola.

3) To assess the effectiveness of structured teaching programme regarding knowledge on non communicable diseases among class IV workers.

4) To associate the post test level of knowledge of class IV workers regarding non-communicable diseases with demographic variable in KLE'S Institute Ankola.

5) The investigator assumed that a structured teaching programme will be effective for increasing their knowledge regarding NCDs

\section{Hypothesis}

H1:- There will be significant statistical association between pre-test knowledge score on non communicable diseases 


\section{International Journal of Science and Research (IJSR) \\ ISSN (Online): 2319-7064}

Index Copernicus Value (2013): 6.14 | Impact Factor (2015): 6.391

with selected demographic variables of class VI workers of KLE's Institute, Ankola at 0.05 level of significance.

H2:- There will be significant gain in knowledge on non communicable among selected class VI workers Ankola through structured teaching programme.

An extensive review of literature was done which enabled the investigator to study in depth the selected problems, to develop conceptual frame work to construct the tool, analysis of data and for interpretation.

Pre- experimental design with one group pre-test and posttest design was adopted to evaluate the effectiveness of STP on knowledge. The study was confined to KLE.S Institute Ankola. The sample size selected was 30 students by using simple random sampling.

The data was collected by using structured questionnaire schedule. The data generated through the study was tabulated and analyzed by using descriptive and inferential statistics.

The study indicates that majority of subjects $46.66 \%$ (14) belonged to age group of 30-40 years. The subjects were male $60.66 \%$ (18) and female $40 \%$ (20). All of the subjects were Hindu $100 \%$ (30). Majority of the subject were married $66.66 \%$ (20). The family income of the majority of the subjects $76.66 \%$ (23) were $10,000-25,000$ per year.

Maximum workers $56.66 \%$ have previous knowledge about NCDs. The source of information of maximum workers was $20 \%$ (6) were through television and others.

The distribution of pre-test knowledge score. The knowledge scores were distributed with a mean of 12.36 , median 12.5, mode 2.1 and standard deviation of 4.19.

The distribution of post-test knowledge score. The knowledge scores were distributed with a mean of 22.99 , median 23.5, mode 28 and standard deviation of 7.45 .

The paired ' $t$ ' test established at 0.05 level of significance revealed that mean posttest knowledge of the sample is significantly higher than their mean pretest knowledge which shows that calculated value is greater than the table value. Hence null hypothesis $\left(\mathrm{H}_{\mathrm{o}}\right)$ was rejected and research hypothesis was accepted indicating that there was significant gain in knowledge on NCDs through Structured teaching programme.

The chi-square established at 0.05 level of significance denotes the association between the knowledge and demographic variables. Age, religion and family income per year were more than the tabulated value hence an association was found among demographic variables, but that of gender, marital status, previous knowledge, source of information and experience any NCDs were less than the tabulated value hence no association was found.

This study provided an enriching experience for the investigator to conduct research project. It also made the investigator to realize the need for knowledge regarding the NCDs. Therefore there is an urgent need to spread public awareness regarding NCDs. The experience gained during the study will help the investigator to take up other research studies in future.

\section{References}

[1] 2008-2013 Action plan for the global strategy for the prevention and control of non-communicable disease WHO; 2008.

[2] Guyatt GH, Oxman AD, Kunz R, Atkins D, Brozker, visit $\mathrm{G}$ etal. Grade guidelines 2. Framinng the question and deciding on important outcomes. $\mathbf{J}$ clin epidermal. 2011; 64(4):395 -400 [pubmed].

[3] Shea BJ, Grimshaw JM, well GA, Boers M, et al. Development of AMSTAR: a measurement tool to assess the methodological quality of systematic reviews. BMC. Med. Res. Methodol 2007; 7:10 [PMC free article] [pubmed].

[4] Standards of medical care in diabetes-2010. Diabetes care. 2010; 33 suppl 1:s11-s61. [PMC] free article] [pubmed].

[5] Maggio CA, Pi-sunyer FX. The prevention and treatment of type 2 diabetes. Diabetes care. 1997; 20 (11): 1744-66. [pubmed]

[6] Morris JN, Crawford MD; Crawford (December 1958) 'Coronary heart disease and physical activity of work evidence of a national necropsy survey.' Br Med J2 (5111): 1485-96.

[7] 'NCD' net- Global non communicable disease Network world health organization.

[8] Basccnthappa BT "Nursing research ( $1^{\text {st }}$ edition) (2005) Jaypee brother published prt ltd pp: 115 .

[9] Global handbook on non-communicable diseases and health promotion. https://books. Google.co.in.

[10] American Journal of preventive Medicine. WWW.ajpmonline.org.

[11] Park K. Park's Text book of preventive and social medicine, 2007published by $\mathrm{m} / \mathrm{s}$ BanarasidasBhanat $19^{\text {th }}$ Edition Pg.127-134.

[12] Multi-Morbidity of non communicable diseases and equity in... www.ncbi.nim.nib.gov/pubmed/23961989.

[13] Adrogue HJ, Barrero J, EkwyanG. Salutary effects of modest fluid replacement in the treatment of adults with diabetic. JAMA. 1989; 262(15): 2108-13 [pubmed].

[14] Cryer PE. Hypoglycemia, functional brain failure, and brain death. J. Clin. Invert. 2007: 117 (4): 86870 [pubmed].

[15] Cryer PE, Davis SN, Shamoon H. Hypoglycemia in diabetes. Diabetes care. 2003; 26(6): 1902-12. [pubmed].

[16] Cheung N,Initchell P, wong TY. Diabetic retinopathy. Lancet 2010; 376(9735): (24-36) [pubmed].

[17] Wright JM, Musini VM. First-line drugs for hypertension. Cochrane, database. Syst. Rev. 2009; (3):cdoo1841.[pubmed]

[18] Drug interaction charts. Online database. University of Liver pool; 2011[11 July 2011] www.hivdruginteractions.

[19] Ray GM. Antiretroviral and statin drug interactions. Cardiol Rev.2009; 17(1): 44.7 [pubmed].

[20] TukaramZagade, Asha Pratinidhi "Effectiveness of Educational Intervention on Knowledge and Practice among Biomedical Waste Handlers" International

\section{Volume 5 Issue 6, June 2016 www.ijsr.net}




\section{International Journal of Science and Research (IJSR) \\ ISSN (Online): 2319-7064}

Index Copernicus Value (2013): 6.14 | Impact Factor (2015): 6.391

Journal of science and Research Volume 3 Issue 5, May 2014: 285 to295.

[21] TukaramZagade,Amol Patil " Effectiveness of Self Instructional Module on Knowledge Regarding Prevention of Micro vascular and Macrovasclar Complications among Patients with Diabetes Mellitus" International Journal of science and Research Volume 3 Issue 5, May 2014: 902 to 908.

[22] NileshPendase, TukaramZagade "Knowledge and Attitude Regarding Health Hazards of Mobile Phone Users among the Junior College Students" International Journal of science and Research Volume 3 Issue 5, May 2014 (IJSR):554 to 561.

[23] AmoshTalsandekar,TukaramZagade "Effectiveness of Learning Package on Knowledge about CardioRespiratory Assessment Among under Graduate student Nurses" International Journal of science and Research Volume 3 Issue 5, May 2014: 548 to 553.

[24] Asha Pratinidhi, TukaramZagade, Satish V Kakade "Effectiveness of Educational Intervention on Practice among Biomedical Waste Handlers" International Journal of science and Research Volume 3 Issue 8, August 2014: 1885 to1891.

[25] RitzE, orth SR. Nephropathy in patients with type 2 diabetes mellitus. N. Engt.J.Med.1999; 341(15):112733 [pubmed].

[26] Prevention of cardiovascular disease. Pocket Guidelines for assessment and management of cardiovascular risk. Geneva: World Health Organization; 2009.

[27] Saenz A, Fernandez- Esteban I, Mataix A, Ausejo M, diabetes mellitus. Cochrane. Patabase. syste. Rev. 2005; (3): CD OO2966 [pubmud].

[28] Thomas DE, Elliott EJ. The use of low- glycaemic index diets indiabetes control. Br. J. IV utr 2010; 104 (6): 797-802.

[29] Maggio CA, pi-sunyerFx. The prevention and treatment of obesity. Application to type 2 diabetes, Diabetes care. 1997; 20(11): 1744-66 [pubmed].

[30] Patel A, Macmabon S, chalmers J, IVeal B, Billot L, Woodward M, et al. Intensive blood glucose control and vascular outcomes in patients with type 2 diabtes. N. Engl. J. med.2008; 358 (24): 2560-72. [pubmed].

[31] Hotman RR, paulsk, Bethel MA, Matthews PR, Neil HA. Lo-year follow-up of intensive glucose control in type 2 diabetes. N. Engl. J. Med.2008; 359(15): 157789 [pubmed].

[32]Definition and diagnosis of diabetes mellitus and intermediate hyperglycemia. Geneva; World Health Organization; 2006.

[33] Standards of medical care in diabetes-2010; 33 suppl 1: s11-s61. (pmc free article) [pubmed].

[34] Global status report on non communicable diseases 2010. Geneva; World Health Organization; 2011.

[35]2008-2013 Action plan for the Global strategy for the prevention and control of non communicable diseases WHO; 2008.

[36] Package of essential non communicable (PEIV) Disease interventions for primary health care in low-resource setting. Geneva: World Health Organization; 2010.

\section{Author Profile}

Prasanna Deshpande is Principal, KLES Institute of nursing sciences, Ankola( U K) Karnataka

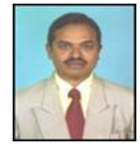

Prof. Tukaram B. Zagade.M.Sc.(N)PGDMLS is Professor, Département of Médical-Surgical Nursing, Krishna Institute of Nursing Sciences, Krishna Institute of Médical Sciences Deemed University, Karad-415539 (Mahārāshtra), India.MOB. 09881678505 Email tbzagade@yaho.co.in 